Original Article

\title{
Role of Rivaroxaban in Patients with Cerebral Venous Thrombosis
}

\author{
Syed Arslan Haider ${ }^{1}$, Huma Batool ${ }^{2}$, Shahid Mukhtar ${ }^{1}$, Athar Iqbal ${ }^{3}$, Shoaib Luqman ${ }^{4}$ \\ Adnan Tariq ${ }^{5}$ \\ ${ }^{1}$ Department of Neurology, Punjab Institute of Neurosciences, Lahore Pakistan. \\ ${ }^{2}$ Department of Pulmonology, Lahore General Hospital (LGH), Lahore Pakistan. \\ ${ }^{3}$ Department of Neurology, Sheikh Zayed Hospital, Lahore Pakistan. \\ ${ }^{4}$ Department of Neurology, Bahawalpur Victoria Hospital, Bahawalpur, Pakistan. \\ ${ }^{5}$ Department of Neurology, Mayo Hospital, Lahore Pakistan.
}

\section{ABSTRACT}

Objective: Cerebral venous thrombosis is a common neurological disease. It has been treated so far with Warfarin that needs continuous monitoring of PT (prothrombin time) and INR (International Normalization Ratio) with potential complications due to this problem. Newer oral anticoagulants have been recommended for other thromboembolic events like pulmonary embolism and can be a good alternative treatment of CVT. We determined the effectiveness of new oral anticoagulant Rivaroxaban in patients with cerebral venous thrombosis.

Material and Methods: The study was conducted in the indoor department of Neurology, Punjab Institute of neurosciences for 1year. Magnetic cerebral venography (MRV) Brain was done at the start of Rivaroxaban, at 3 months and at 6 months where needed. The bias effect was removed by getting MRV done and reported from the same department.

Results: A total of 18 patients were enrolled in the study. One patient was lost to followup. Mean age of our patient data was $28.66 \pm 6.66 .16$ (88\%) patients were females and $2(11 \%)$ were males. 9 patients $(50 \%)$ had clinical and radiological recovery based on MRV brain at 3 months.7 patients (38\%) had recovery based on clinical and radiological parameters at 6 months. Only 1 patient had partial recanalization but that also improved clinically.

Conclusion: Rivaroxabancan is a very effective alternative for warfarin in cerebral venous sinus thrombosis which will avoid concerns commonly encountered with warfarin.

Keywords: Cerebral Venous Thrombosis (CVT), Prothrombin Time (PT), Activated Partial Thromboplastin Time (APTT), Magnetic Resonance Venogram (MRV), Magnetic Resonance Imaging (MRI), Central Nervous System (CNS), Space Occupying Lesion (SOL).

Abbreviations: CVT: Cerebral Venous Thrombosis. PT: Prothrombin Time. APTT: Activated Partial Thromboplastin Time. MRV: Magnetic Resonance Venogram. MRI: Magnetic Resonance Imaging. CNS: Central Nervous System. SOL: Space Occupying Lesion. INR: International Normalization Ratio). CT: Computed Tomography Scan.

Corresponding Author: Dr. Syed Arslan Haider

Department of Neurology, Punjab Institute of Neurosciences,

Lahore - Pakistan

Email: drarslan4@gmail.com

Date of Submission: 16-09-2021
Date of Revision: 25-09-2021

Date of Acceptance: 29-09-2021

Date of Online Publishing: 30-09-2021

Date of Print: 30-09-2021

DOI: $10.36552 /$ pjns.v25i3.595 


\section{INTRODUCTION}

Cerebral venous sinus thrombosis, as the name indicates is the formation of a clot within the dural venous sinuses with the prevalence of 5 people per million annually and magnitude is $0.5 \%$ to $1 \%$ of all strokes. ${ }^{1}$ The symptom of cerebral venous thrombosis (CVT) could be due to raised intracranial pressure in the form of headache, blurring of vision, or due to focal pathology inside the brain resulting in focal neurological deficit or fits. ${ }^{2}$ A different presentation of CVT could be like benign intracranial hypertension. ${ }^{3}$ A $40 \%$ of people have seizures, although it is more common in women who develop sinus thrombosis in pregnancy and postpartum.

Genetic or acquired prothrombotic states can lead to cerebral venous thrombosis. ${ }^{2}$ Proteins $C, S$, and antithrombin III deficiency lead to prothrombotic states. ${ }^{4}$ Another predisposing factor is the use of oral contraceptives ${ }^{4}$. $2 \%$ of strokes in pregnancy are attributable to CVT. ${ }^{5}$ Cancer poses a predisposition to CVT. ${ }^{6}$ In children with parameningeal infections cause CVT. ${ }^{7}$

We started investigation from basics in the form of PT, APTT, Complete blood count, which shows anemia, infection, inflammation, or genetic prothrombotic conditions. Lumbar puncture is not done in all cases but only in those cases where the infection is suspected. It should not be done in patients with focal neurological deficits. Abnormalities on lumbar puncture include elevated opening pressure witha mild rise in cell count and proteins ${ }^{2}$. D-dimers can be used as a sensitive marker to exclude the diagnosis of CVT. ${ }^{8}$

Neuroimaging is vital for investigation, however, CT brain plain has a low sensitivity of $30 \% .{ }^{9} \mathrm{MRI}$ and MRV are the gold standard tools to see the absence of flow voids and intraluminal thrombosis. ${ }^{10-14}$

The current study was aimed at finding an effective and safe alternative to warfarin (due to its frequent and complicated monitoring and risk of intracranial bleed) ${ }^{15}$ as treatment of CVT.

\section{MATERIAL AND METHODS}

\section{Study Setting}

The study was conducted in the indoor department of Neurology, Punjab Institute of neurosciences (PINS). The study was conducted after the approval from the institute's ethical committee for research/clinical trials. Study was conducted for 1 year from Dec 01, 2019, to Nov 30, 2020. Informed consent was taken from each patient.

\section{Inclusion Criteria}

All patients in the adult age group i.e., above 14 years, diagnosed cases of non-infected CVT on a clinical basis (Isolated intracranial hypertension syndrome (headache with or without vomiting, papilledema, and visual problems), focal syndrome (focal deficits, seizures, or both), encephalopathy (multifocal signs, mental status changes, stupor, or coma). The radiological basis was verified on MRV brain and both genders were included in this study.

\section{Exclusion Criteria}

Patients of age less than 14 years were excluded. CVT cases due to CNS infections were not included. Cases of rising intracranial pressure due to (space occupied lesion) SOL were excluded from the study.

\section{Clinical Management}

MR cerebral venography (MRV) Brain was done at the start of Rivaroxaban, at 3 months and at 6 months where needed. The bias effect was removed by getting MRV done and reported from the same department. Data was collected on a predesigned proforma. Results were analyzed through SPSS version 25. 


\section{RESULTS}

\section{Age and Gender Distributions}

A total of 18 patients were enrolled in the study. One patient lost to follow up. The mean age of our patient data was $28.66 \pm 6.66$ years. $16(88 \%)$ patients were female and (11\%) 2 were male patients as shown in Table 1.

Table 1: Distribution of Age.

\begin{tabular}{cccc|} 
Sr. No & Age Group & $\begin{array}{c}\text { Number of } \\
\text { Patients }\end{array}$ & Percentage \\
1. & $15-19$ & 02 & $11.11 \%$ \\
2. & $20-29$ & 07 & $38.8 \%$ \\
3. & $30-40$ & 09 & $50.0 \%$ \\
\hline
\end{tabular}

\section{Patterns of Recovery}

9 patients (50\%) had clinical and radiological recovery based on MRV brain.7 patients (38\%) had recovery based on clinical and radiological parameters at 6 months. Only one patient (5.5\%) had only clinical recovery with partial recanalization. Patterns of recovery are shown in Table 2.

Table 2: Patterns of recovery.

\begin{tabular}{lc} 
Recovery & Frequency (n \%) \\
Recovery at 3 months & $9(50 \%)$ \\
Recovery at 6 months & $8(38 \%)$ \\
Total & $17(94.4 \%)$ \\
Missing & $1(5.5 \%)$ \\
Total & $18(100 \%)$ \\
\hline
\end{tabular}

\section{STRATIFICATION OF DATA}

\section{1) Symptoms and signs}

16 (88\%) cases had a headache as the presenting feature while $08(44 \%)$ cases had a focal neurological deficit. 04 (22\%) cases had altered mental status as depicted in Table 3.

\section{2) Risk Factors}

10 (55\%) cases were having pregnancy and puerperium is a risk factor for CVT. Oral contraceptives were noted in 2 (11\%) cases as a risk factor. Other risk factors like deep venous thrombosis and systemic lupus erythematosus were noted in $2(11 \%)$ cases as shown in Table 3.

\section{3) Sinuses Involved}

As shown in table 3, 04 (22\%) cases had transverse and superior sagittal sinus involvement each. 02 (11\%) had sigmoid sinus involvement while $01(5 \%)$ had straight sinus involvement. 06 (33\%) patients had a combination of involvement of different sinuses.

\begin{tabular}{lcc}
\hline $\begin{array}{l}\text { Table 3: Stratification of data with different } \\
\text { parameters. }\end{array}$ & \\
Parameters & Frequency & Percentage \\
Symptoms and Signs & & \\
Headache & 16 & $88 \%$ \\
Focal deficit & 08 & $44 \%$ \\
Mental status changes & 04 & $22 \%$ \\
Risk Factors & & \\
Pregnancy and & 10 & $55 \%$ \\
puerperium & 02 & $11 \%$ \\
Oralcontraceptives & 0 & \\
Malignancy & & $11 \%$ \\
Others & 2 (DVT and SLE*) \\
Sinuses Involved & & \\
Superior sagittal sinus & 04 & $22 \%$ \\
Transverse sinus & 04 & $22 \%$ \\
Sigmoid sinus & 02 & $11 \%$ \\
Straight sinus & 01 & $05 \%$ \\
Combination & 06 & $33 \%$ \\
\hline
\end{tabular}

*DVT: Deep venous thrombosis

*SLE: Systemic lupus erythematosus

\section{DISCUSSION}

We compared our study with international data and found the following studies. In 2014, 16 patients were included in a study, and 7 were treated with Rivaroxaban. $93.8 \%$ of cases had a successful recovery, and all patients showed at 
least partial recanalization. One patient in the warfarin group and 2 patients in the Rivaroxaban group had minor bleeding. The study revealed that Rivaroxaban had a similar clinical yield as warfarin and can be used as an effective alternative. $^{12}$

A $2^{\text {nd }}$ study studied the effectiveness of Rivaroxaban in the treatment of CVT. ${ }^{13}$ Total of 6 cases were enrolled in the study and $83 \%$ had partial recanalization at $3-6$ months while $100 \%$ had recanalization at 12 months. There was no recurrence of CVT in any of the cases. The $3^{\text {rd }}$ comparison for our results came from an observational study conducted at different centers in $2019 .^{14}$ Total 111 patients were included in the study, out of the total pool 45 patients were given Rivaroxaban 66 had warfarin. At discharge 34/45 had MRS grades from 0 to 2 in the Rivaroxaban group and 46/66 in the warfarin group.

At 6 months $35 / 39$ had adequate functional recovery in the Rivaroxaban group while 44/56 in the warfarin group. These results reinforced the similar efficacy of Rivaroxabanif not superior to warfarin in the treatment of CVT. Esmaeili et al, studied a comparison of Rivaroxaban and warfarin in 23 and 13 patients respectively. ${ }^{16}$ They found that optimal mRS (modified ranking scale) score was obtained in $9 / 10$ patients with Rivaroxaban while 19/22 patients getting warfarin. MRV showed partial or complete recanalization in $12 / 14$ patients receiving Rivaroxaban while all patients had recanalization in the warfarin group. No significant difference was noted in the two groups regarding complication in the form of hemorrhage. Maqsood et al. studied the same in 45 patients with 21 in Rivaroxaban and 24 in the warfarin group. ${ }^{17}$ They documented recanalization in $86 \%$ of cases of the Rivaroxaban group and $83 \%$ warfarin group at 6 months and $100 \%$ at 12 months. NIHSS (National Institute of Health Stroke Scale) score of 0 was obtained in $95 \%$ of Rivaroxaban group at follow up on $3^{\text {rd }}$ to $12^{\text {th }}$ month. No significant bleeding episodes were reported in either group. They concluded that Rivaroxaban is a promising option to treat cerebral venous thrombosis. Data similar to our study was found in a study enrolling 20 patients to be treated with rivaroxaban. ${ }^{18}$ They found that $95 \%$ of cases had a good recovery, $60 \%$ had partial and $40 \%$ had complete recanalization. No case was reported to have a hemorrhage in this study.

\section{CONCLUSION}

Rivaroxaban can be effectively used as an alternative to warfarin in the treatment of CVT while avoiding the potential and well-known limitations of warfarin treatment. We need to be a little more proactive in the stratification of our data to have our guidelines keeping in mind our local concerns.

\section{Limitations}

Our study had a limited data size that needs to be further extended to increase the impact and have more generalized results.

\section{REFERENCES}

1. Bousser MG, Ferro JM. Cerebral venous thrombosis: an update. Lancet Neurol. 2007; 6: 162-170.

2. Ferro JM, Canhão $P$, Stam J, Bousser MG, Barinagarrementeria $\mathrm{F}$; ISCVT Investigators. Prognosis of cerebral vein and dural sinus thrombosis: results of the International Study on Cerebral Vein and Dural Sinus Thrombosis (ISCVT). Stroke, 2004; 35: 664-670.

3. Biousse V, Ameri A, Bousser MG. Isolated intracranial hypertension as the only sign of cerebral venous thrombo15sis. Neurology, 1999; 53: 1537-1542.

4. Martinelli I, Sacchi E, Landi G, Taioli E, Duca F, Mannucci PM. High risk of cerebral-vein thrombosis in carriers of a prothrombin-gene 
mutation and in users of oral contraceptives. N Engl J Med. 1998; 338: 1793-1797.

5. James $A H$, Bushnell $C D$, Jamison MG, Myers ER. Incidence and risk factors for stroke in pregnancy and the puerperium. Obstet Gynecol. 2005; 106: 509-516.

6. Rogers LR. Cerebrovascular complications in patients with cancer. Semin Neurol. 2004; 24: 453460.

7. Damak M, Crassard I, Wolff V, Bousser MG. Isolated lateral sinus thrombosis: a series of 62 patients. Stroke, 2009; 40: 476-481.

8. Cucchiara B, Messe S, Taylor R, Clarke J, Pollak E. Utility of D-dimer in the diagnosis of cerebral venous sinus thrombosis. J Thromb Haemost. 2005; 3: 387-389.

9. Leach JL, Fortuna RB, Jones BV, Gaskill-Shipley MF. Imaging of cerebral venous thrombosis: current techniques, spectrum of findings, and diagnostic pitfalls. Radiographics, 2006; 26 (Suppl. 1): S19S41.

10. Boukobza M, Crassard I, Bousser MG, Chabriat H. MR imaging features of isolated cortical vein thrombosis: diagnosis and follow-up. AJNR Am J Neuroradiol. 2009; 30: 344-348.

11. Medel R, Monteith SJ, Crowley RW, Dumont AS. A review of therapeutic strategies for the management of cerebral venous sinus thrombosis. Neurosurg Focus, 2009; 27 (5): E6 (ISSN: 10920684).

12. Geisbüsch $C$, Richter $D$, Herweh $C$, Ringleb PA, Nagel S. Novel factor xa inhibitor for the treatment of cerebral venous and sinus thrombosis: first experience in 7 patients. Stroke, 2014 Aug; 45 (8): 2469-71.

13. Anticoli S, Pezzella FR, Scifoni G, Ferrari C, Pozzessere $C$. Treatment of cerebral venous thrombosis with rivaroxaban. J Biomed Sci. 2016; 5 (3): $1-2$.

14. Wasay $M$, Khan $M$, Rajput HM, Farooq $S$, Memon MI, Al-Rukn SA, Malik A, Abd-Allah F, Shoaib RF, Shahid $R$, Nishat $S$. New oral anticoagulants versus warfarin for cerebral venous thrombosis: a multicenter, observational study. Journal of Stroke, 2019; 21 (2): 220.

15. Ahmad Y, Lip GY. Stroke prevention in atrial fibrillation: where are we now? Clinical Medicine Insights: Cardiology, 2012; 6: CMC-S8976.

16. Esmaeili S, Abolmaali M, Aarabi S, Motamed MR, Chaibakhsh S, Joghataei MT, Mojtahed M, Mirzaasgari Z. Rivaroxaban for the treatment of cerebral venous thrombosis. BMC Neurology, 2021; 21 (1): 1-6.

17. Maqsood $M$, Imran Hasan Khan $M$, Yameen $M$, Aziz Ahmed K, Hussain N, Hussain S. Use of oral rivaroxaban in cerebral venous thrombosis. Journal of Drug Assessment, 2021; 10 (1): 1-6.

18. Iyer RS, Ramakrishnan TC, Akhtar S, Muthukalathi K, Kumar P, Muthukumar K. Is it safe to treat cerebral venous thrombosis with oral rivaroxaban without heparin? A preliminary study from 20 patients. Clinical Neurology and Neurosurgery, 2018; 175: 108-11.

\section{Additional Information}

Disclosures: Authors report no conflict of interest.

Ethical Review Board Approval: The study was conformed to the ethical review board requirements.

Human Subjects: Consent was obtained by all patients/participants in this study.

\section{Conflicts of Interest:}

In compliance with the ICMJE uniform disclosure form, all authors declare the following:

Financial Relationships: All authors have declared that they have no financial relationships at present or within the previous three years with any organizations that might have an interest in the submitted work.

Other Relationships: All authors have declared that there are no other relationships or activities that could appear to have influenced the submitted work. 


\section{AUTHORS CONTRIBUTIONS}

\begin{tabular}{|l|l|l|}
\hline Sr.\# & Author's Full Name & Intellectual Contribution to Paper in Terms of: \\
\hline 1. & Syed Arslan Haider & Study design and methodology. \\
\hline 2. & Huma Batool & Paper writing and data calculations. \\
\hline 3. & Shahid Mukhtar & Data collection and calculations. \\
\hline 4. & Athar lqbal & Analysis of data and interpretation of results etc. \\
\hline 5. & Adnan Tariq & Literature review and referencing. \\
\hline
\end{tabular}

